\title{
Correspondence
}

Correspondents should note that space is limited and shorter letters have a greater chance of publication. The Editors reserve the right to cut letters and also to eliminate multitudinous references. Please try to be concise, strictly relevant and interesting to the reader, and check the accuracy of all references in Journal style.

\section{WHOSE DILEMMA? THE CRISIS OF THE MENTAL HEALTH SERVICES}

DEAR SIR,

I understand that you are unwilling to allow lengthy debates or polemics in the pages of the Journal. However, I should like to respond, albeit briefly, to a few points raised by Professor Jones' recent commentary on my work (Journal, September 1982, 141, 221-26).

Those who are concerned with the future of the mental health services confront, as Professor Jones rightly suggests, a dilemma: "if it is wrong to get patients out of the mental hospital, and wrong to keep them in, what are we to do with them?" In seeking a way out of this double-blind, we must, it seems to me, remain sceptical of the painless solutions we are usually offered in the guise of "reforms". No informed person, least of all myself, could view with equanimity the prospect of once more consigning chronic psychotics to the Victorian bins in which they were traditionally stored. There are clearly a substantial number, however, for whom some form of more or less permanent sheltered environment is abolutely essential. For the still larger proportion for whom noninstitutional forms of care are in principle preferable, the central requirement is for adequate communitybased support and care: the kind of infrastructure which is presently all but entirely absent. Bitter experience ought by now to have taught us to scorn millennial claims that adoption or rejection of the asylum will substantially ameliorate the mental patient's situation. We must recognize instead that neither institutional treatment nor community care is in any sense a panacea; and that both, if inadequately funded, provide ample opportunity for, and plenty of concrete examples of squalor, neglect, abuse, and inhumanity.

Pace Professor Jones' bizarre suggestion that I am a "radical non-interventionist", the whole thrust of my critique of contemporary policies is towards a condemnation of dressing up malign neglect as humanitarian concern. So far from sharing the naive romanticism of many of my sociological colleagues, who assume that the mental patient's difficulties flow more or less exclusively from the application of pernicious psychiatric labels, I would insist that serious discussion of this subject must begin with a recognition of the disturbance, disorder, and profound alienation that constitute serious forms of madness. It is precisely these features of the condition that make provision of good communal and institutional care so essential. It is precisely the powerlessness of those who require help and the structural biases of the social system in which we live that make it so unlikely that either will be forthcoming.

University of California, San Diego, La Jolla, California 92093

\section{NEUROLEPTIC-INDUCED CATATONIC SYMPTOMS}

DeAR Sir,

Neuroleptic drugs can cause a syndrome very similar to catatonia with withdrawal, mutism, posturing, rigidity, immobility and waxy flexibility, but although several cases have been reported over the last twenty years this phenomenon does not appear to be widely known (Brenner and Rheuban, 1972; De, 1973; Gelenberg and Mandel, 1977; May, 1959; Regenstein, Alpert and Reich, 1977; Weinberger and Kelley, 1977; Weinberger and Wyatt, 1978).

It may be very difficult to distinguish schizophrenic catatonia from this reaction, and often the final diagnosis arrived at is one of catatonic schizophrenia. However Ayd suggests in 'Haloperidol Update 195880 ' that nowadays catatonia as a side-effect of neuroleptic drugs is actually a commoner phenomenon than catatonic schizophrenia, and he advises that clinicians should presume that neuroleptic drugs are responsible whenever catatonic symptoms appear shortly after the start of neuroleptic therapy (Ayd, 1981). Since potentially fatal medical complications may follow, he advises that neuroleptic therapy be stopped immediately, although the catatonic symptoms may continue for a while due to the long elimination half-life of neuroleptics such as haloperidol.

Another case of catatonia which appears to be neuroleptic-induced is now reported:

The patient was a sixteen-year-old girl of Chinese- 